\title{
Investigation of Leakage Current Waveforms Recorded in a Coastal High Voltage Substation
}

\author{
D. Pylarinos \\ Dept of ECE \\ University of Patras \\ Greece \\ dpylarinos@yahoo.com
}

\author{
K. Siderakis \\ Dept of EE \\ TEI of Crete \\ Greece
}

\author{
E. Pyrgioti \\ Dept of ECE \\ University of Patras \\ Greece
}

\author{
E. Thalassinakis \\ Assistant Director \\ P.P.C. \\ Greece
}

\author{
I. Vitellas \\ Director \\ P.P.C. \\ Greece
}

\begin{abstract}
Leakage current monitoring is a widely employed technique to monitor the performance of outdoor insulation. The investigation of leakage current waveforms offers significant information since the waveforms' shape has been well correlated with different types of surface activity. Field waveforms are not often considered and investigated due to technical difficulties and the long term monitoring required for recording activity portraying waveforms. Therefore, the basic stages of activity have been defined mostly through accelerated lab tests. However, lab tests do not reproduce exact field conditions and therefore field activity may differ from the one recorded in the lab. In this paper, an investigation of $L C$ waveforms recorded in a heavily polluted site, over more than 6 years of monitoring, is presented. A large variety of waveform shapes are portrayed and various correlations with world experience are made. In addition, recorded data is also investigated in order to identify field related noise. The need for added categorization criteria in the case of field measurements is discussed.
\end{abstract}

Keywords- field; insulator; leakage current; noise; waveform; monitoring; pollution;

\section{INTRODUCTION}

One of the main problems concerning outdoor insulation is the pollution phenomenon, which is rather intense in areas located near the sea. Leakage current (LC) monitoring is a widely employed tool, used to monitor and investigate surface activity and insulation's performance. Contamination combined with wetting, in the case of ceramic insulators, results to the formation of a conductive film on the insulator's surface, which permits the flow of leakage current which in turn can result to the formation of dry bands, arcing and eventually flashover [1]. Polymer insulators and coatings are used as an improvement to ceramic insulators because of their hydrophobic surface which results to the formation of water droplets on the surface, instead of a film [2-5]. However, hydrophobicity is suppressed and recovered due to aging and the environmental and electrical stress applied [2, 3]. Therefore, activity similar to the one recorded on ceramic insulators, is recorded on polymer insulators during hydrophobicity loss periods.

Leakage current waveforms portraying different stages of activity have been described by various researchers. A detailed review can be found in [6]. The basic discrete stages of activity consists of resistive sinusoid waveforms due to the presence of a conductive film on the insulator surface, distorted sinusoid waveforms as an intermediate stage and dry band arcing that causes a time lag of current onset. Pulses have been reported to superimpose on LC and the appearance of such pulses has been correlated with corona discharges and short arcing [6]. Recorded waveforms however do not always correspond clearly to a certain stage. This may not be reported in accelerated lab tests, but becomes evident in case of field LC waveform monitoring [7]. In the field, activity is not straight forward, surface conductivity may change rapidly or gradually, different parts of the insulator may be subjected to different conditions and surface condition may also vary from part to part. All these factors result to a variety of complex waveforms.

In this paper, an investigation of LC waveforms recorded in a heavily polluted site over a significant time period, that exceeds 6 years, is presented. A large variety of waveform shapes are portrayed and various correlations with world experience are made. Rcorded data is also investigated in order to identify field related noise.

\section{EXPERIMENTAL SET UP}

The LC measurements under investigation have been performed in the $150 \mathrm{kV}$ Linoperamata Transmission Substation which is located in Heraklion, Crete right next to the sea coast [8], and therefore suffers intense marine pollution. The waveforms investigated and presented in this paper are recorded on $150 \mathrm{kV}$ post insulators (porcelain, composite and porcelain coated with RTV SIR) which are part of the grid. No distinction is made in this paper regarding the material of the insulator.

The measurement of leakage current is acquired by inserting a collection ring and a Hall sensor in the LC path. The acquired data are transmitted to a central data acquisition system (DAS). The waveform portraying the highest LC peak value in a user-defined time window is recorded [9]. Each waveform has time duration of $480 \mathrm{~ms}$. Custom-made software was developed to manage LC waveforms [10]. The measuring system is shown in Figure 1. Specifications of the monitoring system are shown in Table 1. 
TABLE I. SPECIFICATIONS OF THE MONITORING SYSTEM

\begin{tabular}{|c|c|}
\hline \multicolumn{2}{|l|}{ Leakage current inputs } \\
\hline Number of channels: & $9 \times$ current inputs \\
\hline Input measuring range: & 2 ranges $\pm 500 \mathrm{~mA}$ and $3 \mathrm{~A}$ peak \\
\hline Sensor Packaging: & weatherproof metal enclosure \\
\hline Safety Features: & Galvanically isolated up to $6 \mathrm{KV}$ \\
\hline Resolution: & $350 \mathrm{uA} / 2 \mathrm{~mA}$ \\
\hline \multicolumn{2}{|l|}{ Signal Acquisition } \\
\hline Resolution: & 12 bit or $0.05 \%$ of full scale \\
\hline Overall accuracy at $25^{\circ}$ : & $0.5 \%$ of full scale \\
\hline Sampling Rate: & $2 \mathrm{kHz}$ continuously \\
\hline Sampling methods: & $\begin{array}{l}\text { All channels sampled continuously \& } \\
\text { simultaneously }\end{array}$ \\
\hline \multicolumn{2}{|r|}{ 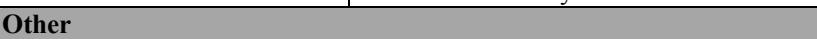 } \\
\hline Communication: & RS232 \\
\hline Communication speed: & $56 \mathrm{~K}$ baud \\
\hline Packaging: & metal enclosure \\
\hline Time Stamping: & battery backed real time clock \\
\hline Storage device: & on-board flash memory \\
\hline Base Unit Dimensions: & $175 \times 290 \times 370 \mathrm{~mm}$ \\
\hline Weight: & $15 \mathrm{~kg}$ \\
\hline AC Power Supply: & $\begin{array}{l}110 / 230 \mathrm{VAC}, 50 / 60 \mathrm{~Hz} \text { (with dip/sag } \\
\text { ride through capability) }\end{array}$ \\
\hline Power Usage: & $30 \mathrm{VA} \mathrm{DC}$ \\
\hline Power Input: & $\begin{array}{l}12 \text { VDC (No dip ride through } \\
\text { capability) }\end{array}$ \\
\hline Operating system: & Microsoft Windows 95/NT4+ \\
\hline Data representation: & Graphical + ASCII format \\
\hline
\end{tabular}

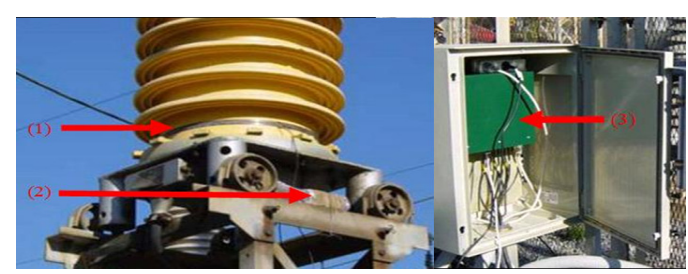

Fig. 1. The measuring system: 1 . The collection ring 2. The Hall sensor 3. The DAS

\section{INVESTIGATION OF FIELD LC WAVEFORMS}

Leakage current waveform monitoring has been performed by various researchers both in lab and field and a detailed review of measuring and analyzing $\mathrm{LC}$ on insulators and specimens can be found in [6]. As a general rule, it is reported that as activity advances, the amplitude of the leakage current increases and that initial activity (resistive sinusoid current) is usually rather small. In the field, pollution, stress and surface condition vary with location (different parts of the insulator) and also with time. Therefore, further investigation is performed in order to get an exact image of the activity experienced in the field and the resulting LC waveforms.

\section{A. $\quad$ Sinusoid Waveforms}

Typical sinusoid waveforms recorded are shown in Figure 2. The vast majority of the sinusoid waveforms recorded, portrayed small amplitude (under $2 \mathrm{~mA}$ ) similar to the one shown in Figure 2A. However the amplitude range varies due to its dependence on the electric resistance of the conductive film on the insulator's surface. Because of this, sinusoid waveforms of amplitude much higher than usually reported [6] have been recorded in the considered site, due to heavy pollution and the high voltage stress applied. The amplitude of the largest recorded sinusoid (Figure 2D) slightly exceeds $29 \mathrm{~mA}$.

\section{B. Distorted Sinusoid Waveforms}

A large variety of distorted sinusoid waveforms have been recorded and some typical waveforms are illustrated in Figure 3. No correlation could be established between waveform amplitude and type of distortion. Distorted waveforms of large amplitude have also been recorded. The amplitude of the largest recorded distorted sinusoid (Figure 3D) slightly exceeds $49 \mathrm{~mA}$.

\section{Dry Band Arcing}

Formation of a dry band results to a large part of the voltage applied on the band and arcing occurs when the surrounding air of the dry band cannot withstand that voltage. The resulting waveform illustrates a time lag of current onset and higher LC peaks as shown in Figure 4. Investigation of the waveforms showed that arcs can extinct gradually (Figure 4A) or rapidly (Figure 4D), and also ignite gradually (Figure 4D) or rapidly (Figure 4C). Arcs can be distinct (Figure 4C and Figure 4D) or consequent (Figure 4E). The amplitude of an arc can exhibit gradual increase and decrease before its extinction (Figure 4A, Figure 4B, Figure 4E). Finally arc duration can exceed the length of the time window (Figure 4F).

\section{Pulses}

Pulses are recorded superimposed on various waveform types, as illustrated in Figure 5. Pulses have been recorded superimposed on waveforms portraying null activity (Figure $5 \mathrm{~A}$ ), sinusoid and distorted sinusoid waveforms (Figure 5B$5 \mathrm{~K})$ and they can appear in the same waveform with a dry band arc-like discharge (Figure 5I, Figure 5K). The frequency of pulses' appearance varies and pulses can appear on consequent half cycles (Figure 5C, Figure 5F, Figure 5G), on consequent cycles in the negative of positive part (Figure 5D, Figure 5E, Figure 5K) or on non-adjacent cycles (Figure 5B). The amplitude of pulses also varies. The smallest pulse recorded portrays a peak value of about $5 \mathrm{~mA}$, while pulses in the area of $100 \mathrm{~mA}$ have also been recorded (Figure 5C, Figure 5E). The size of pulses compared to the amplitude of the waveforms that are superimposed to, also varies. Pulses can illustrate comparable (Figure 5F, Figure 5G, Figure 5H, Figure 5I, Figure 5K), noticeably larger (Figure 5B, Figure 5D) or exceptionally larger amplitude than the rest of the waveform (Figure 5A, Figure 5C, Figure 5E). The position of pulses is always at the peak of half-cycles, but sometimes exhibit a small shift to the right (Figure 5F, Figure 5H, Figure 5I, Figure 5K), remaining however at the crest of the waveform. The duration of pulses also varies, and pulses may appear narrow (Figure 5E, Figure $5 \mathrm{~F}$, Figure $5 \mathrm{H}$ ) or broad (Figure $5 \mathrm{~A}$, Figure $5 \mathrm{~B}$ ). Both narrow and broad pulses can appear in the same waveform in different cycles (Figure 5C, Figure 5I, Figure 5K). The orientation of pulses also varies, and waveforms that portray mainly positive (Figure 5B, Figure 5C, Figure 5G, Figure 5I, Figure $5 \mathrm{~K}$ ) or negative pulses (Figure $5 \mathrm{D}$, Figure $5 \mathrm{E}$ ) have been recorded. Some or all of these behaviours can co-exist in 
the same waveform (Figure 5C, Figure 5G, Figure 5H, Figure 5I, Figure 5K). Even isolated pulses have been recorded (Figure 5A).

\section{E. Complexity of Field LC Waveforms' Shape}

The waveform shape does not always safely correlate to one of the basic stages. Different types of activity can be present on the same waveform, exhibiting similar amplitude but different shape. In addition the transition sequence between different types of activity can vary. Figures $6 \mathrm{~A}-6 \mathrm{~F}$ and Figures $7 \mathrm{~A}-7 \mathrm{~F}$ are presented to better illustrate the complexity that can be recorded in field waveforms.
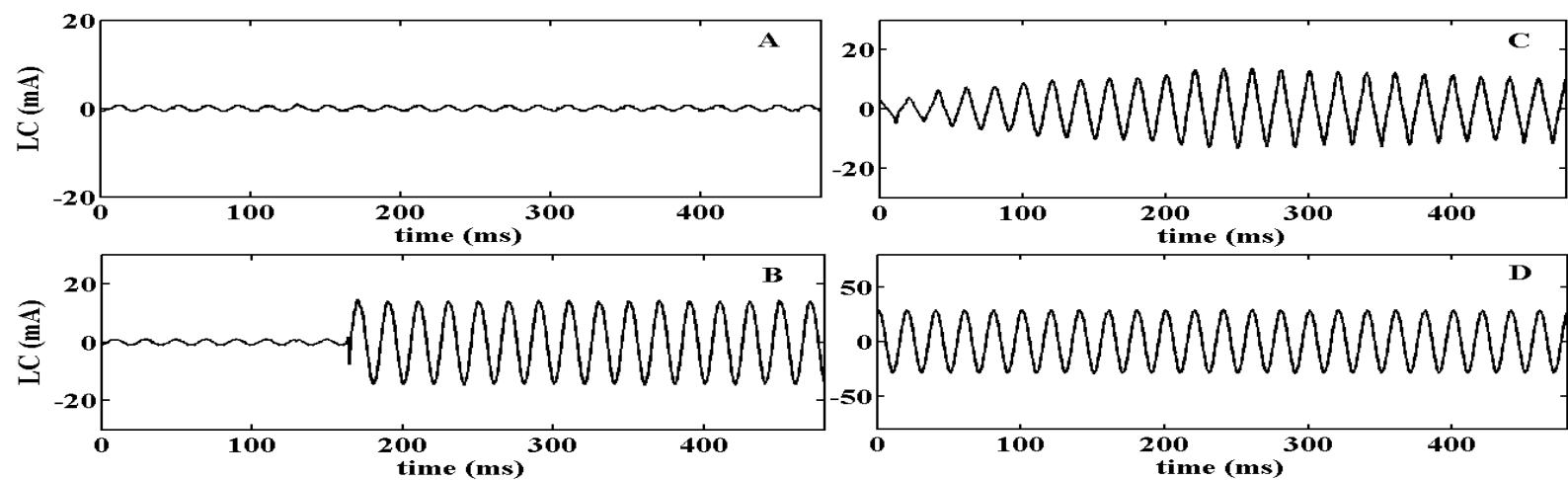

Fig. 2. Sinusoid waveforms portraying A. low amplitude B. rapid conductivity increase C. gradual conductivity increase D. large amplitude
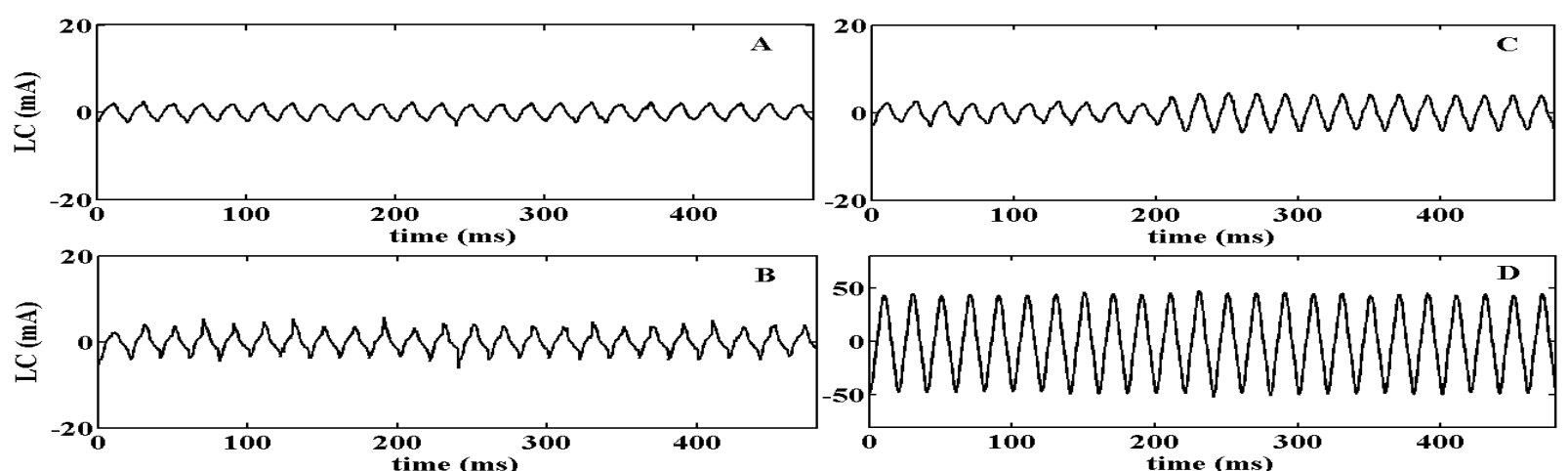

Fig. 3. A-B. distorted sinusoids, C. distorted sinusoid portraying conductivity increase D. the largest recorded distorted sinusoid
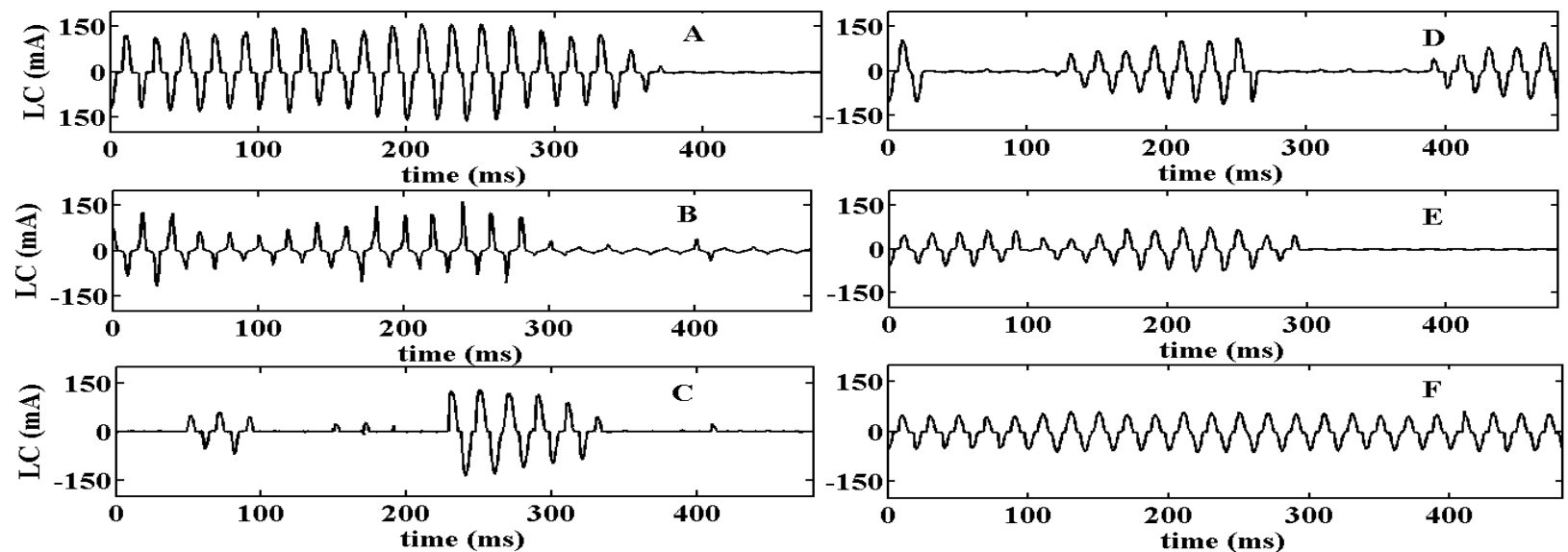

Fig. 4. Waveforms portraying dry band arcing 

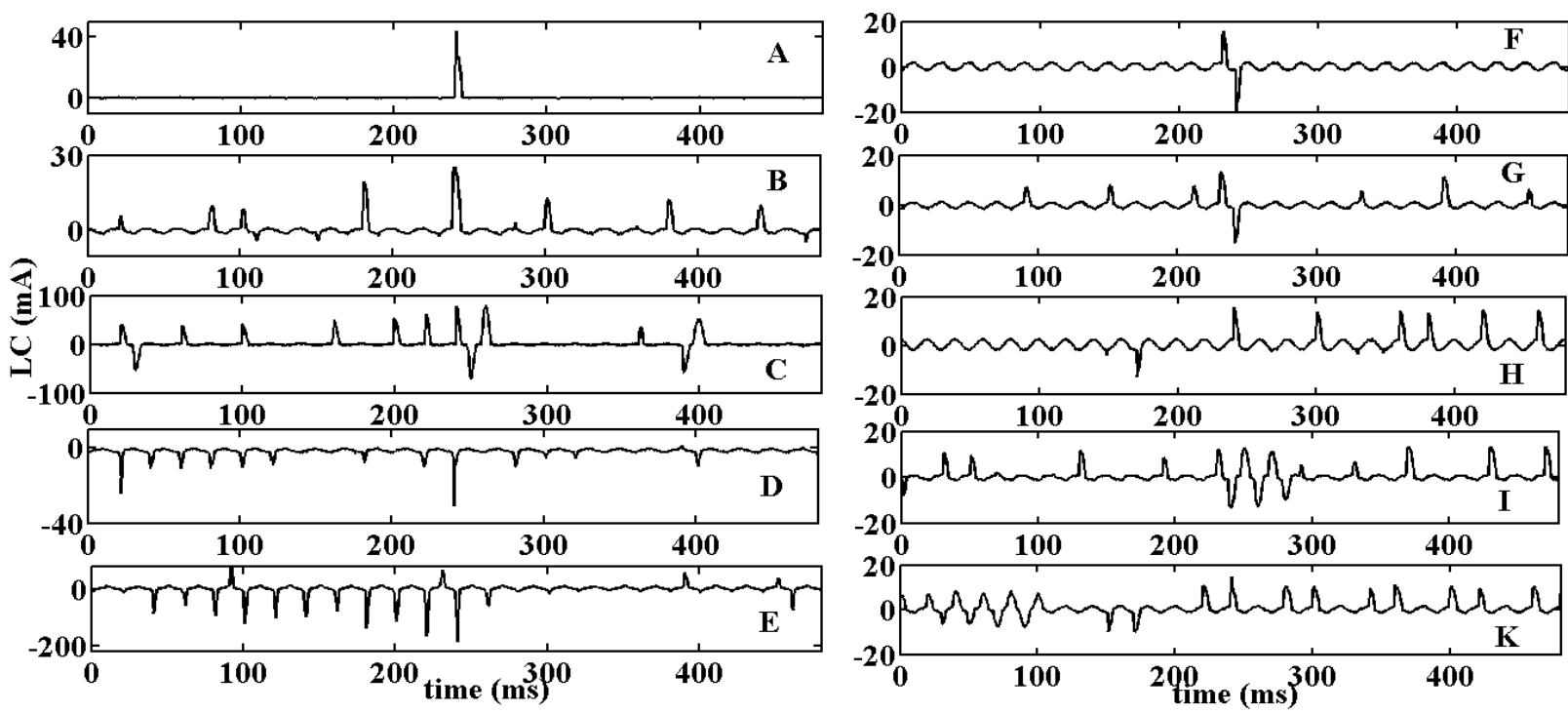

Fig. 5. Pulses superimposed on the waveforms' crest
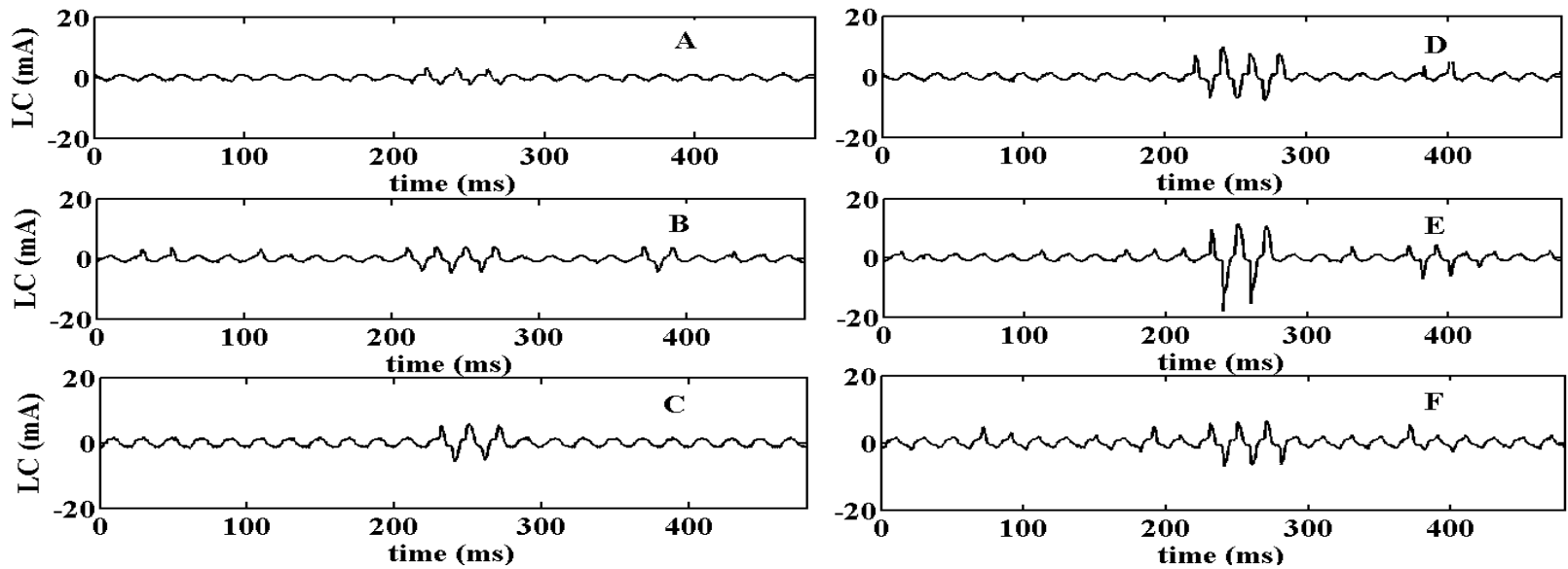

Fig. 6. Various Leakage Current Waveforms
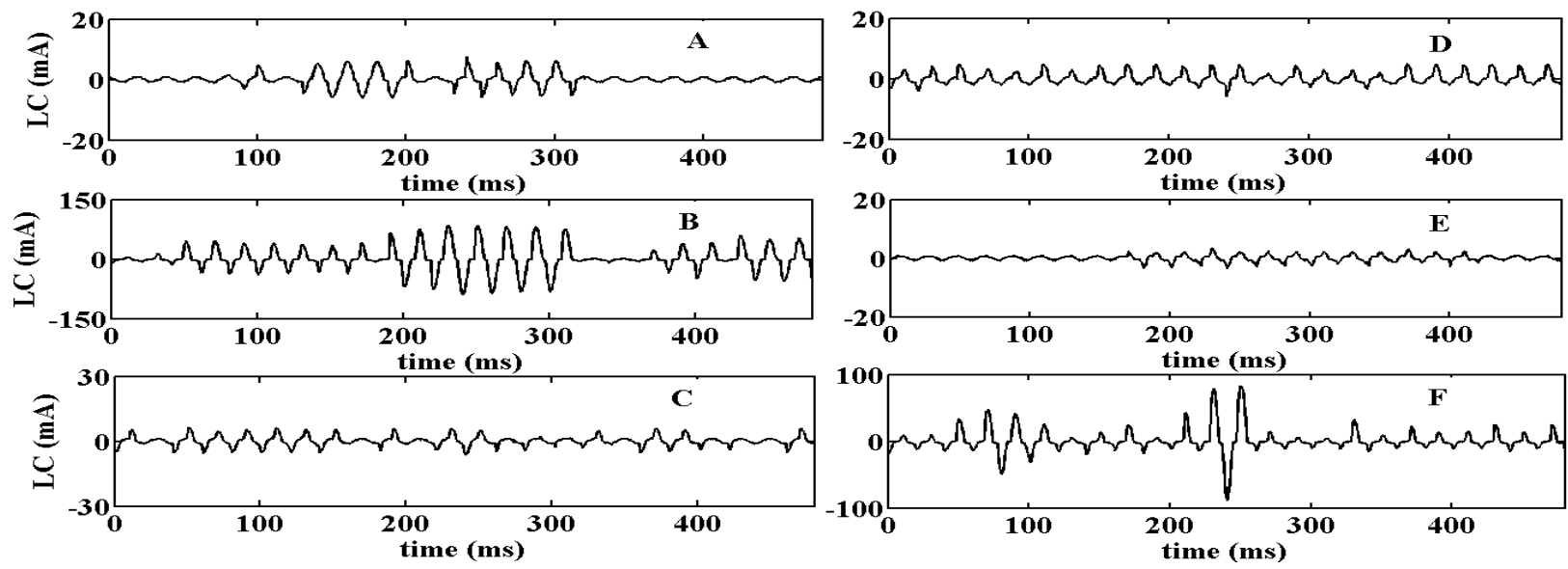

Fig. 7. Various Leakage Current waveforms 


\section{FIELD NOISE}

Limited access, long term monitoring and field conditions result to a variety of noise related waveforms. Investigation of the recorded waveforms lead to the identification of three different types of noise: Typical Noise, Dysfunction Generated Noise and Single Point Noise [9]. Typical noise (noise which is always present) consists of random minor peaks that exhibit amplitude in the range of $1 \mathrm{~mA}$, as illustrated in Figure $8 \mathrm{~A}$ and Figure $8 \mathrm{~B}$. That means that measurements in the typical noise area are usually incoherent and that, since meagre or no activity is the usual case, a large number of typical noise waveforms are recorded [9]. Single point noise results to a single point recorded far from the rest of the waveform. Such single points are found superimposed on all types of waveforms (Figures $8 \mathrm{C}-8 \mathrm{~F}$ ), even those portraying typical noise (Figure $8 \mathrm{C}$ ) and dry band arcing (Figure 8F). Such points do not always follow the current trend as shown in Figure 8D and Figure 8E.
A large amount of dysfunction generated waveforms has been recorded and some typical waveforms are shown in Figures 9A-9F. Their origin cannot be strictly defined, since monitored insulators are part of the grid and any crucial event happening on the grid (e.g. switching, faults etc) could lead to a temporary chaotic LC measurement as the ones shown in Figure 9. It should be noted that two sensor faults occurred during the monitoring time. The sensors were replaced shortly after their damage. However, dysfunction generated waveforms have been recorded on all channels, even those that didn't suffer from a sensor fault, and during different time periods. It is not unusual for normal waveforms to be recorded shortly after the recording of a dysfunction generated waveform, frequently at the very next time window.
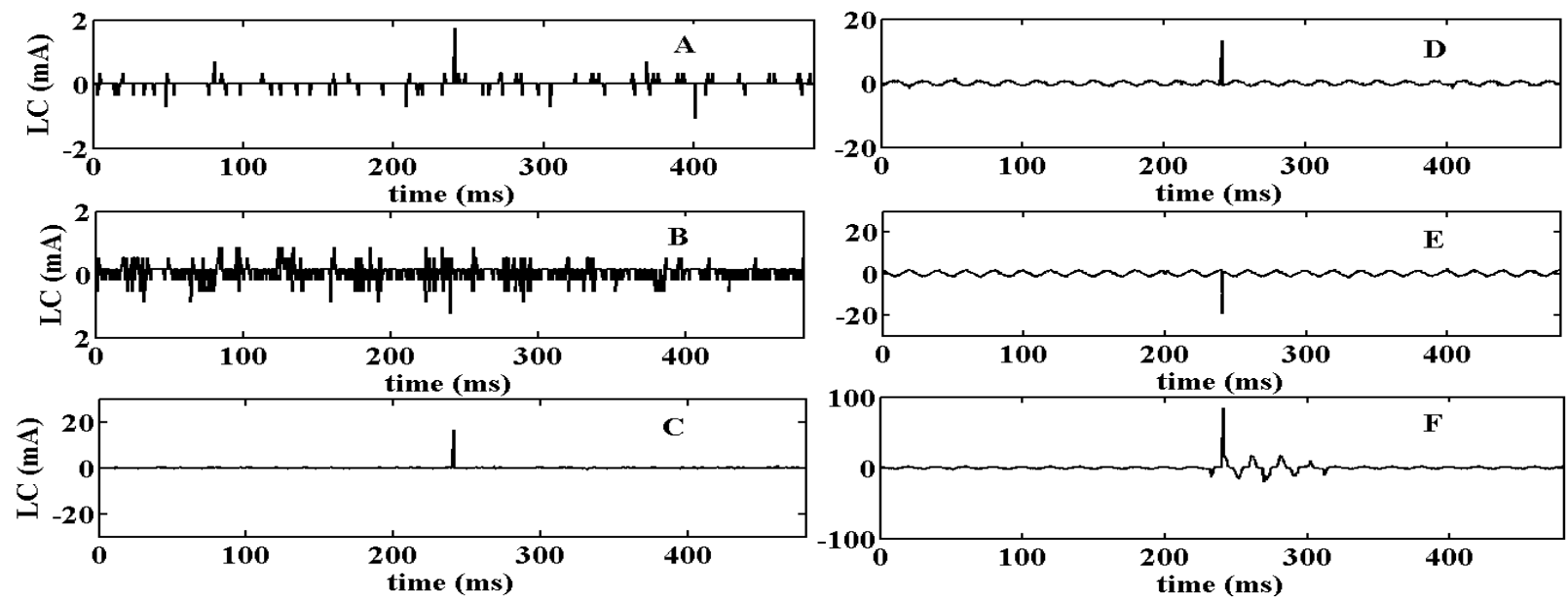

Fig. 8. A-B. Typical Noise C-F. Single Point Noise
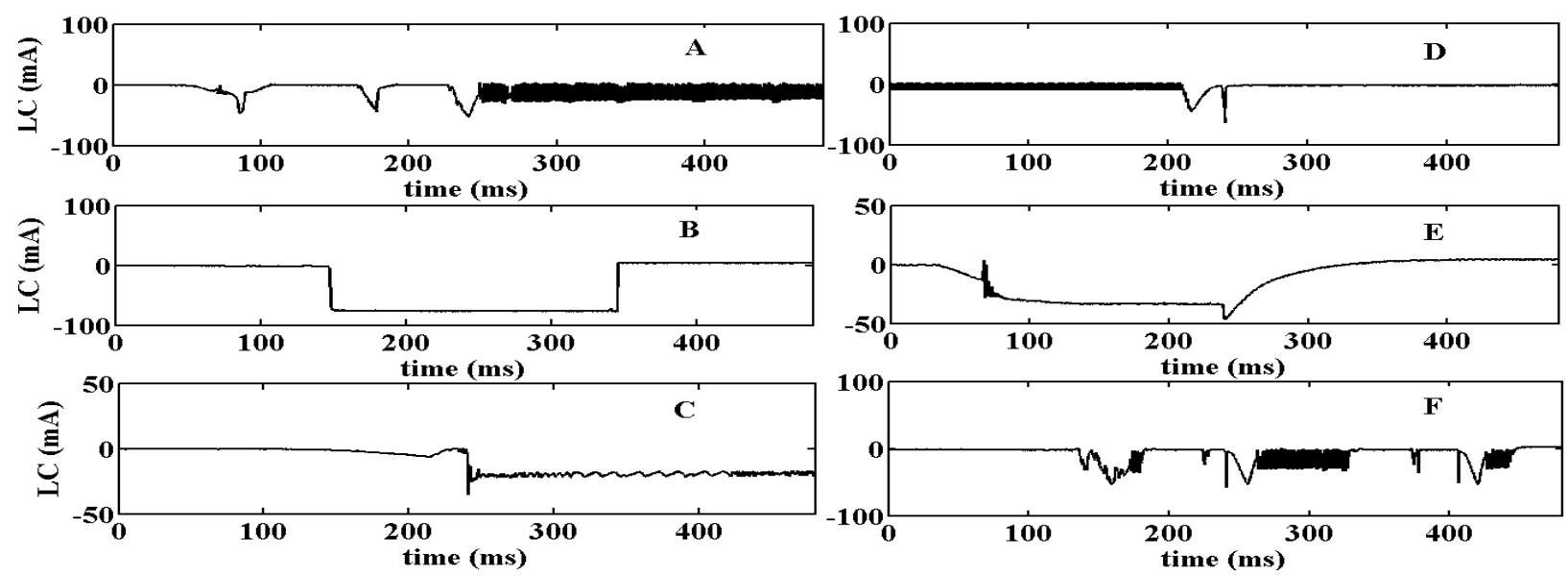

Fig. 9. Dysfunction Generated Noise 


\section{DISCUSSION \& FUTURE WORK}

A large variety of LC waveform shapes and several parameters influencing the waveform shape have been recorded and investigated. Several waveform shapes have been presented in order to highlight certain attributes such as:

- The portrayed noise generated waveforms hints that a field reduction/removal stage should be designed to cope with the noise problem. A possible solution for this problem has been proposed by the authors in [9].

- Sinusoid waveforms that portray gradual and rapid amplitude changes have been recorded (Figure 2B-2C), reflecting the changes in surface film's conductivity, which in turn can be gradual or rapid. This should be expected in field measurements where the insulator is subjected to field conditions and should be considered if differential current values are calculated in order to detect arcing as in [11].

- In the case of distorted waveforms, rapid transitions between different distortion types and amplitudes have been recorded, as shown in Figure 3C. It should be mentioned that no distinct correlation could be established between waveform amplitude and type of distortion. Such changes may be attributed to chemical changes in the pollutant layer as described in [12] or to hydrophobicity class changes as described in [13].

- The appearance of pulses has been correlated with the severity of the test conditions, the existence of high saltdensity fog, short strong discharges and corona discharges [6]. However, it should be noted that the waveforms shown in this papers hints that yet undefined conditions seem to favour either positive or negative pulses.

- The existence of complex waveforms hints that further categorization of LC waveforms may be necessary in the case of field measurements. It has been proposed in [14] that the duration of the activity can be used to further categorize waveforms, and that seems to be the next logical step. Such a criterion can be used to categorize waveforms as e.g. intense or short discharges based on whether the activity exceeds an arbitrary selected number of half-cycles. However, investigation of field waveforms in this paper shows that discrimination between e.g. a heavily distorted half-cycle and a discharge portraying half-cycle may be difficult and therefore an added criterion should be applied for that discrimination.

\section{CONCLUSION}

The measurement of leakage current is a well established technique, employed worldwide in order to monitor and investigate surface activity and field performance of high voltage insulators. In this paper, an investigation of LC waveforms recorded over a significant time period, in a coastal transmission substation is performed. The insulators monitored are part of the grid, installed in the $150 \mathrm{kV}$ side of the substation, suffering from intense marine pollution. Investigation of the recorded waveforms verified the basic waveform shapes described in the literature. However, several new attributes of such waveforms are reported and discussed in this paper. It is shown that further categorization could prove necessary in the case of long term field measurements.

\section{REFERENCES}

[1] CIGRE SC 33 TF 33.04.01, "Polluted insulators: a review of current knowledge", Technical Brochure No158, 2000

[2] N. Yoshimura, S. Kumagai, S. Nishimura, "Electrical and environmental aging of silicone rubber used in outdoor insulation", IEEE Trans. Dielectr. Electrical Insulat., Vol. 6, No. 5, pp. 632-650, 1999

[3] H. Hillborg, U. W. Gedde, "Hydrophobicity changes in silicone rubbers", IEEE Trans. Dielectr. Electrical Insulat., Vol. 6, No. 5, pp. 703-717, 1999

[4] K. Siderakis, D. Agoris, "Performance of RTV silicone rubber coatings installed in coastal systems", Electr. Power Syst. Res., Vol. 78, No. 2, pp. 248-254, 2008

[5] K. Siderakis, D. Pylarinos, E. Thalassinakis, I. Vitellas, E. Pyrgioti, "Pollution maintenance techniques in coastal high voltage installations", Eng. Technol. Appl. Sci. Res., Vol. 1, No. 1, pp. 1-7, 2011

[6] D. Pylarinos, K. Siderakis, E. Pyrgiot, "Measuring and analyzing leakage current for outdoor insulators and specimens", Rev. Adv. Mater. Sci., Vol. 29, No. 11, 2011

[7] D. Pylarinos, K. Siderakis, E. Pyrgioti, E. Thalassinakis, I. Vitellas, "Monitoring leakage current waveforms in the field", DEMSEE 5th international conference and technical exhibit on Deregulated Electricity Market issues in South-Eastern Europe, Sitia, Greece, 2010

[8] D. Pylarinos, K. Siderakis, E. Thalassinakis, I. Vitellas, E. Pyrgioti, "Recording and managing field leakage waveforms in Crete installation, measurement, software development and signal processing", IEEE 16th International Conference on Intelligent System Application to Power Systems, Hersonissos, Greece, 2011

[9] D. Pylarinos, K. Siderakis, E. Pyrgioti, E. Thalassinakis, I. Vitellas, "Impact of noise related waveforms on long term field leakage current measurements", IEEE Trans. Dielectr. Electr. Insul., Vol. 18, No. 1, pp. 122-129, 2011

[10] D. Pylarinos, "A custom-made MATLAB based software to manage leakage current waveforms”, Eng. Technol. Appl. Sci. Res., Vol. 1, No. 2, pp. 36-42, 2011.

[11] M. Otsubo, T. Hashiguchi, C. Honda, O. Takenouchi, T. Sakoda, Y. Hashimoto, "Evaluation of insulation performance of polymeric surface using a novel separation technique of leakage current", IEEE Trans. Dielectr. Electrical Insulat, Vol. 10, No. 6, pp. 1053 - 1060, 2003

[12] Waluyo, P. M. Pakpahan, Suwarno, M.A. Djauhari, "Study on leakage current waveforms of porcelain insulator due to various artificial pollutants", World Academy of Science, Engineering and Technology, Vol. 32, pp. $293-298,2007$

[13] M. A. R. M. Fernando, S. M. Gubanski, "Leakage current patterns on contaminated polymeric surfaces", IEEE Trans. Dielectr. Electrical Insulat., Vol. 69, No. 5, pp. 688-694, 1999

[14] M. Sato, A. Nakajima, T. Komukai, T. Oyamada, "Spectral Analysis of Leakage Current on contaminated insulators by auto regressive method", Conference on Electrical Insulation and Dielectric Phenomena, Annual Report, pp. $64-66,1998$

\section{AUTHORS PROFILE}

Dionisios Pylarinos was born in Athens in 1981. He received a Diploma degree in Electrical and Computer Engineering from the University of Patras in 2007. Presently he is with the High Voltage Laboratory of the Department of Electrical and Computer Engineering at the University of Patras. He has worked as a scientific consultant for PPC. His research interests include outdoor insulation, electrical discharges, signal processing and pattern recognition.

Kiriakos Siderakis was born in Heraklion in 1976. He received a Diploma degree in Electrical and Computer Engineering in 2000 and the Ph.D. degree in 2006 from the University of Patras. Presently, he is an Application 
Professor at the Department of Electrical Engineering, at the Technological Educational Institute of Crete. His research interests include outdoor insulation, electrical discharges, high voltage measurements and high voltage equipment diagnostics and reliability.

Eleftheria Pyrgioti was born in 1958 in Greece. She received her Diploma degree in Electrical Engineering from Patras University in 1981 and the Ph.D. degree from the same University in 1991. She is an assistant professor at the department of Electrical and Computer Engineering at the University of Patras. Her research activity is directed to high voltage, lightning protection, insulation coordination and distributed generation.

Emmanuel Thalassinakis received the Diploma in Electrical and Mechanical Engineering and also the Ph.D. degree from the National Technical University of Athens. After working for the Ministry of the Environment, in 1991 he joined the Public Power Corporation (P.P.C.) where he is now Assistant Director of the Islands Network Operations Department.

Isidoros Vitellas was born in 1954 in Greece. He has a diploma in Electrical Engineering and the Ph.D. degree in the same field. He is currently Director of the Islands Network Operations Department in P.P.C. (Public Power Corporation) Athens, Greece. 